\title{
The Simple Analytics of Optimal Growth with Illegal Migrants
}

\author{
Bharat R. Hazari and Pasquale M. Sgro
}

School of Economics

Deakin University

$$
n^{\circ} 2003-01
$$

Address for Correspondence

Professor Pasquale Sgro

School of Economics

Deakin University

221 Burwood Highway

Victoria 3125Australia

August 2002 


\section{Abstract : The Simple Analytics of Optimal Growth with Illegal Migrants}

This paper analyses the impact of illegal migration on the optimal path of domestic (resident) consumption. The analysis draws two important conclusions. First, if illegal migrants and domestic labour are perfect substitutes, illegal migration necessarily lowers the long-run per capita consumption of domestic residents. Second, if illegal migrants and domestic labour are imperfect substitutes, the effect on the long-run per capita domestic consumption is ambiguous, however, in the CobbDouglas case, the result is clear cut and per capita domestic consumption rises as a result of illegal migration.

Résumé : Une analyse simple de croissance optimale en présence d'immigration clandestine

Dans cet article nous analysons les effets de l'immigration clandestine sur le sentier optimal de consommation nationale (des résidents). Nous obtenons deux conclusions importantes. D'abord, si les immigrants clandestins et le travail des nationaux sont des substituts parfaits, l'immigration illégale réduit dans le long terme la consommation par tête des nationaux. Ensuite, si les immigrants clandestins et le travail des nationaux sont des substituts imparfaits, l'effet sur la consommation par tête de long terme des nationaux est ambigu. Cependant, dans le cas d'une fonction de production de Cobb-Douglas, nous obtenons un résultat clair qui est que la consommation par tête augmente à la suite d'une entrée d'immigrants clandestins.

JEL classification: F2, 04

Keywords: Illegal migrants, domestic consumption, growth.

$\underline{\text { Mots clés }}$ : Immigrants clandestins, consommation nationale, croissance. 


\section{The Simple Analytics of Optimal Growth with Illegal Migrants*}

\section{INTRODUCTION}

Illegal migrants are present in the workforce of many countries. Due to a variety of social, political and economic factors, many countries no longer search for, deport or punish illegal migrants. Their presence is ignored by enforcement authorities and they are employed openly in selected industries. Illegal migrants are frequently hired by the hospitality industry; as carers for infants and the elderly and as domestic workers. For example, in Italy and France the general populace recognises the presence of illegal migrants and the service they provide. Groups of illegal migrants in shopping thoroughfares sell cheap merchandise to locals. As a result of the nature of employment which illegal migrants undertake, it is most appropriate to model them in terms of a multisectoral model of growth. However, in this paper we derive results only on the basis of a one-sector growth model. This is being done for the sake of mathematical simplicity and to gain insights into the working of a growth model with illegal migrants. ${ }^{2}$ This paper models illegal migrants in an optimal growth framework without policing. In many countries enforcement costs may be prohibitive, as is the case in India where the majority of illegal migrants come from neighbouring countries and are thus similar in appearance to the local population. Identification of such migrants is both difficult and costly. This may not be the case in France and Italy which receive coloured and black Africans as illegal migrants. As mentioned earlier, even in these countries the authorities are ignoring the presence of such migrants and saving enforcement costs. ${ }^{3}$

The main purpose of this paper is to analyse the impact of illegal migration on the optimal path of domestic (resident) consumption. We derive two important conclusions. First, if illegal migrants and domestic labour are perfect substitutes, then illegal migration necessarily lowers the long run per capita consumption of domestic residents. Second, in the case where illegal migrants and domestic labour are imperfect substitutes, the ranking of the long run per capita consumption of domestic residents with and without illegal migrants is ambiguous. To obtain an intuitive feel

\footnotetext{
${ }^{*}$ We would like to thank Prasanta Pattanaik, Jean-Michel Grandmont and an anonymous referee for very useful comments and suggestions.
} 
for this result, we use the Cobb-Douglas case. This established that for resident long term per capita consumption to fall, illegal migrants have to be greater than the domestic labour force - a highly unlikely empirical result. Hence, on the basis of the Cobb-Douglas example, the impact of illegal migrants will be to raise the long run per capita consumption of the domestic residents. The important message from a policy perspective is that if illegal migration is to be allowed (not policed), then they should at least be imperfect substitutes for domestic labour.

\section{ONE SECTOR MODEL WITH ILLEGAL MIGRATION}

\section{(a) Perfect substitution between illegal and domestic labour}

It is appropriate now to spell out the one sector model with illegal migrants. The economy produces commodity, $\mathrm{Y}$, with the help of capital, native labour and illegal migrants. The production function for $\mathrm{Y}$ is given below:

$$
Y=F[K, L+M]
$$

where $\mathrm{K}$ denotes capital, L domestic labour and M illegal migrants. Note that illegal migrants and domestic labour are perfect substitutes for each other. Alternatively, we could assume that illegal migrants are a separate factor of production and this case is analysed later in this paper.

The production function is assumed to exhibit constant returns to scale and diminishing returns to factors. It also satisfies the Inada (1966) conditions. In intensive form, the above function can be written as:

$$
y=\frac{Y}{L+M}=f(k)
$$

where $y$ denotes per capita output in terms of total labour and $\mathrm{k}$ the capital intensity, i.e. $k=K /(L+M)$

Profit maximization ensures that:

$$
\begin{aligned}
& r=f^{\prime}(k) \\
& w=f(k)-k f^{\prime}(k)^{2}
\end{aligned}
$$


where $r$ denotes rental on capital, $w$ the wage rate for domestic workers and $f^{\prime}$ the marginal product of capital.

The illegal migrants are paid a wage below that of domestic workers. This occurs as employers exploit the illegal standing of the workers. Such exploitation arises because of the threat that the illegal workers may be reported to the authorities and then deported. It is this implicit threat that results in an exploitative wage rate for migrants, hence:

$$
w_{m}=\beta w \quad 0<\beta<1
$$

The term $\mathrm{w}_{\mathrm{m}}$ denotes the wage for the illegal workers and $\beta$ the differential factor. To capture the exploitation factor, $\beta$ is assumed to be positive and less than unity. The value of $\beta$ will be taken as exogenously given. It is assumed that there is no serious attempt to detect and deport these migrants. A model with detection requires a policing sector which has not been incorporated in this paper. Note that $w_{m} M$, the wage bill of illegal migrants will be assumed to equal their consumption.

We now introduce a migration function to determine the flow of illegal migrants $(\dot{M})$ into the economy:

$$
\dot{M}=\left[\beta \mathrm{w}-\bar{w}_{\mathrm{o}}\right]^{\gamma} \quad 0<\gamma<1
$$

where $\bar{w}_{o}$ is the subsistence or reservation wage in the country of origin of the illegal migrant. It is assumed that migration occurs as long as $\beta w-\bar{w}_{o}>0$ and ceases when $\beta w=\bar{w}_{o}^{4}$.

The static production equilibrium with migration is shown in Figure1. In Figure 1a, the curve $\mathrm{f}(\mathrm{k})$ is drawn in the per capita output $(\mathrm{y})$ and capital intensity $(\mathrm{k})$ space. Let $k^{d}$ represent the domestic capital labour ratio (fixed endowment of $\bar{K}$ and $\bar{L}$ ) with full employment and no illegal migrants. The full employment wage-rental ratio is shown by the distance OS. In Figure $1 \mathrm{~b}$ we show how the level of migration is determined

Figure 1a 
this model. Let $\mathrm{BB}^{\prime}$ be the marginal product curve for labour and $A \mathrm{~B}^{\prime \prime}$ the $\beta w$ curve (equation (5)), showing $\mathrm{M}_{\text {wat }}^{*}$ ue migrants receive at any particular point on the 
$\mathrm{BB}^{\prime}$ curve. Given the reservation (subsistence) wage rate in the home country of the illegal migrants, $\bar{w}_{o}$, we can determine the number of illegal migrants, as shown by $\mathrm{OM}^{*}$. Since these migrants are exploited, the rent received by the migrant receiving country is the area $\bar{w}_{0} C D Z$.

It is appropriate now to introduce the social objective function in the tradition of Ramsey (1928):

$$
\max _{\mathrm{c}} \quad \int_{0}^{\infty} e^{-\rho t} U(c) d t
$$

where $\rho$ represents the social rate of discount and $U(c)$ the utility as a function of domestic consumption per head $(\mathrm{c}=\mathrm{C} / \mathrm{L})$. This is maximized subject to constraints which are now derived. From the definitions of income, investment and payments made to illegal migrants we know that domestic consumption equals

$$
C(t)=Y(t)-\dot{K}-\beta w M
$$

where $\dot{K}$ represents investment. The migrants receive an income that equals $\beta w M$ and they do not save or accumulate capital (their consumption exhausts their income). Depreciation of capital is ignored throughout this paper. The term $\mathrm{C}(\mathrm{t})$ represents total domestic consumption in the economy. As is the practice in the labour mobility literature, the earnings of the illegal migrants are subtracted in computing domestic consumption ${ }^{5}$. Equation (8) is re-written in per capita terms as shown below:

$$
\alpha c=y-\frac{\dot{K}}{L+M}-\frac{\beta w M}{L+M}
$$

where $\alpha=\mathrm{L} /(\mathrm{L}+\mathrm{M})$ which is less than unity. The expression for $\dot{k}$ is now derived. Since $k=K /(L+M)$ it follows that

$$
\frac{\dot{k}}{k}=\frac{\dot{K}}{K}-n \alpha-(1-\alpha) \frac{\dot{M}}{M}
$$


where $\mathrm{n}$ is derived from the growth equation for domestic labour $\mathrm{L}=\mathrm{L}_{0} \mathrm{e}^{\mathrm{nt}}$. Furthermore, assume that the migrant population, after migration ceases, grows at the same rate as the domestic labour force: $M=M_{0} e^{n t}$

Therefore:

$$
\dot{k}=f(k)-\mathrm{nk}-\alpha \mathrm{c}-\beta w(1-\alpha)
$$

To consider the optimal growth path, we need to maximize the discounted value of utility of consumption subject to the constraint, (equation 11), just derived. Using equations (7) and (11) we have:

$$
\underset{\mathrm{c}}{\max } \int_{o}^{\infty} e^{-\rho t} U(c) d t
$$

s.t.

$$
\begin{aligned}
& \dot{k}=f(k)-\mathrm{nk}-\alpha \mathrm{c}-\beta w(1-\alpha) \\
& k(0)=k_{0} \\
& O \leq c \leq f(k)
\end{aligned}
$$

From this formulation, and applying the Maximum Principle, we define the Hamiltonian:

$$
H=U(c) e^{-\rho t}+\mu\left[f(k)-\mathrm{nk}-\alpha \mathrm{c}-\beta\left(f(k)-k f^{\prime}(k)\right)(1-\alpha)\right]
$$

with first order conditions.

$$
\begin{aligned}
& \frac{\partial H}{\partial c}=U_{1}(c) e^{-\rho t}-\mu \alpha=0 \\
& -\frac{\partial H}{\partial k}=\dot{\mu}=-\mu\left[f^{\prime}(k)-\alpha n+(1-\alpha) \beta k f^{\prime \prime}\right]
\end{aligned}
$$

Differentiating (13) yields

$$
\dot{\mu}=\frac{1}{\alpha} \mathrm{e}^{-\rho \mathrm{t}}\left[U_{11}(c) \dot{c}-\rho U_{1}(c)\right]
$$

Equating (14) and (15) we can find 


$$
\dot{c}=\frac{\mathrm{f}^{\prime}(\mathrm{k})-(\mathrm{n}+\rho)+(1-\alpha) \beta \mathrm{kf} \mathrm{f}^{\prime \prime}}{\eta(\mathrm{c})} \mathrm{c}
$$

where $\eta(c)$ is the elasticity with which the marginal utility of consumption declines as consumption increases:

$$
\eta(c)=-c U_{11}(c) / U_{1}(c)
$$

and where $U_{1}$ is the marginal utility and $U_{11}$ is the change in the marginal utility.

We therefore have the following two differential equations:

$$
\begin{aligned}
& \dot{c}=\frac{\mathrm{f}^{\prime}(\mathrm{k})-(\mathrm{n}+\rho)+(1-\alpha) \beta \mathrm{kf}^{\prime \prime}}{\eta(\mathrm{c})} \mathrm{c} \\
& \dot{k}=f(k)-n k-\alpha c-\beta w(1-\alpha)
\end{aligned}
$$

To understand the significance of our results, we plot them in Figure 2. If $\dot{\mathrm{c}}=\mathrm{o}$ then $f^{\prime}(k)=(n+p)-(1-\alpha) \beta k f^{\prime \prime}$. This point is identified as point $\mathrm{A}$ in the top half of Figure 2 and the vertical $\dot{\mathrm{c}}=\mathrm{o}$ curve in the bottom half of Figure 2. To the left of $\dot{\mathrm{c}}=\mathrm{o}$, it is clear that consumption is increasing $\dot{\mathrm{c}}>\mathrm{o}$ and to the right consumption is decreasing $\dot{\mathrm{c}}<\mathrm{o}$. If $\dot{k}=o, c=((f(k)-n k-\beta w(1-\alpha)) / \alpha$ and we can trace out the $\dot{k}=o$ curve in the bottom half of Figure 2. The point B is the balanced growth path of the system with $\mathrm{c}^{*}$ and $\mathrm{k}^{*}$.

Finally, we compare the results of this exercise with those obtained in the standard model without illegal migrants. The $\dot{c}=0$ and $\dot{k}=0$ expressions reduce to the following in the case of zero illegal migration

$$
\begin{aligned}
& f^{\prime}(k)=n+\rho \\
& f(k)=n k+\mathrm{c}
\end{aligned}
$$

and are denoted as $\dot{c}_{O}=0$ and $\dot{k}_{O}=0$ in Figure 2. 
Figure 2
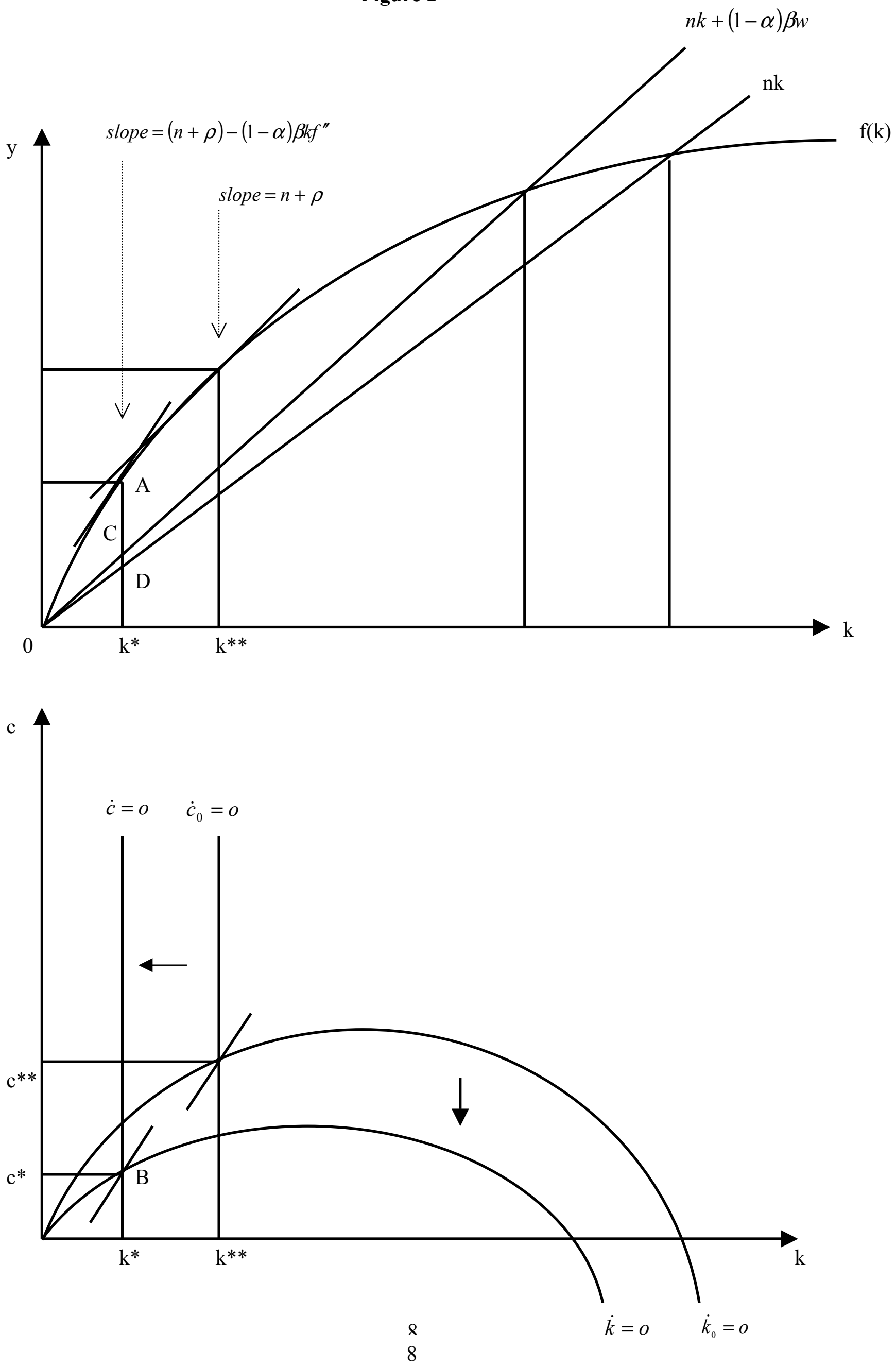
Equations (19) and (20) need to be compared with the corresponding conditions derived from equations (17) and (18)

$$
\begin{aligned}
& f^{\prime}(k)=(n+\rho)-(1-\alpha) \beta k f^{\prime \prime} \\
& f(k)=n k+\alpha c+(1-\alpha) \beta\left(f(k)-k f^{\prime}(k)\right)
\end{aligned}
$$

Comparing (19) and (21) we see that the $\dot{c}_{O}=o$ curve is to the right of the $\dot{c}=o$ curve in Figure 2 since $(n+p)-(1-\alpha) \beta k f^{\prime \prime}>n+\rho$. A comparison of equations (20) and (22) reveals that the $\dot{k}_{O}=0$ curve is everywhere above the $\dot{k}=0$ curve since the slope of $\mathrm{nk}$ is less than the slope of $n k+(1-\alpha) \beta w$ (as w increases with $\mathrm{k}$ ). Hence, $\mathrm{c}^{*}$ and $\mathrm{k}^{*}$ with illegal migration are smaller than $\mathrm{c}^{* *}$ and $\mathrm{k}^{* *}$ respectively.

The presence of illegal migrants has two effects. Since they are being exploited, the domestic residents earn some rent which they can consume and/or save. However, some capital is used up in producing output for consumption by migrants. The first effect adds to domestic consumption and/or investment while the second effect uses up capital. The net effect is negative so that domestic consumption falls as a result of illegal migration.

A further explanation of the fall in $\dot{c} / c$ runs as follows. Suppose that the economy is at a steady state without any migrants, legal or illegal. This economy now receives illegal migrants who are fully employed and consume all of their income. First consider what happens to the capital-labour ratio and per capita income. The $n k$ curve rotates up to $n k+(1-\alpha) \beta w$. Note that $(1-\alpha) \beta w$ denotes the consumption by illegal migrants. This would reach a maximum when $\beta=1$, at which point illegal migrants are not exploited. The capital-labour ratio must fall as a consequence of the inflow of illegal migrants, until it reaches the intersection point between $f(k)$ and $n k+(1-\alpha) \beta w$. The economy has less capital per worker than before migration and is therefore poorer - hence $\dot{c} / c$ for the local population must fall. Note that at point $k^{*}$ in Figure 2 top panel, the consumption by illegal workers is shown by distance CD. It 
should also be noted that exploitation helps in reducing the magnitude of the fall in the per capita consumption of domestic residents.

\section{(b) Imperfect substitution between illegal/domestic labour}

If we model illegal migrants as a separate factor of production, then domestic and foreign labour are no longer perfect substitutes and in this case the analysis becomes more interesting. The production function of $\mathrm{Y}$ changes to:

$$
Y=F(K, L, M)
$$

which in intensive form can be written as

$$
y=Y / L=f(k, m)
$$

where $\mathrm{k}=\mathrm{K} / \mathrm{L}$ and $\mathrm{m}=\mathrm{M} / \mathrm{L}$. The marginal productivity conditions now become

$$
\begin{aligned}
& \mathrm{r}=\mathrm{f}^{\prime}(\mathrm{k}, \mathrm{m}) \\
& w=f(k, m)-k f^{\prime},(k, m)-m g^{\prime}(k, m) \\
& w_{m}=\beta^{\prime} g^{\prime}(k, m)
\end{aligned}
$$

where $f^{\prime}=\partial f / \partial k$ and $g^{\prime}=\partial f / \partial m$.

In this case the illegal worker is not paid the value of his/her marginal product. ${ }^{6}$ This is represented in equation (27) where $0<\beta^{\prime}<1$.

The migration function now alters to

$$
\dot{M}=\left(\beta^{\prime} g^{\prime}-\bar{w}_{0}\right)^{\gamma} \quad 0<\gamma<1
$$

The social objective function (7) remains the same and the domestic consumption is now defined as follows:

$$
C(t)=Y(t)-\dot{K}-w_{m} m
$$

which is converted into per capita terms as follows: 


$$
c(t)=y-\frac{\dot{K}}{L}-w_{m} m
$$

By using the relation between $\dot{K}$ and $\dot{k}$ it follows that:

$$
\dot{k}=f(k, m)-c-n k-w_{m} m
$$

The Hamiltonian for this system is now defined as:

$$
H=U(c) e^{-\rho t}+\mu\left(f(k, m)-c-n k-w_{m} m\right)
$$

with first order condition

$$
\begin{aligned}
& \frac{\partial H}{\partial c}=U_{1}(c) e^{-\rho t}-\mu=0 \\
& -\frac{\partial H}{\partial k}=\dot{\mu}=-\mu\left(f^{\prime}(k)-n-m \frac{\partial w_{m}}{\partial k}\right)
\end{aligned}
$$

Note that $\partial w_{m} / \partial k>O$.

After the usual manipulation we end up with the following differential equations:

$$
\begin{aligned}
& \dot{c}=\frac{f^{\prime}(k, m)-\left(n+\rho+m \partial w_{m} / \partial k\right.}{\eta(c)} c \\
& \dot{k}=f(k, m)-c-n k-w_{m} m
\end{aligned}
$$

In this case by plotting $\dot{c}$ and $\dot{k}$ in Figure 3, we note that the production function $f(k, m)$ now depends on both the capital/labour ratio and the migrant/labour ratio.

The terms $\mathrm{c}^{*}$ and $\mathrm{k}^{*}$ can also be defined for this case but the comparison with the zero migration case is complicated as it is not clear whether the new solution will be to the right or left of the zero migration case. Hence, $\mathrm{c}^{*}$ and $\mathrm{k}^{*}$ with illegal migration may be greater or less than the solution without such migration. Therefore, it is possible for illegal migration to increase the long-term per capita consumption of the residents. 
Figure 3
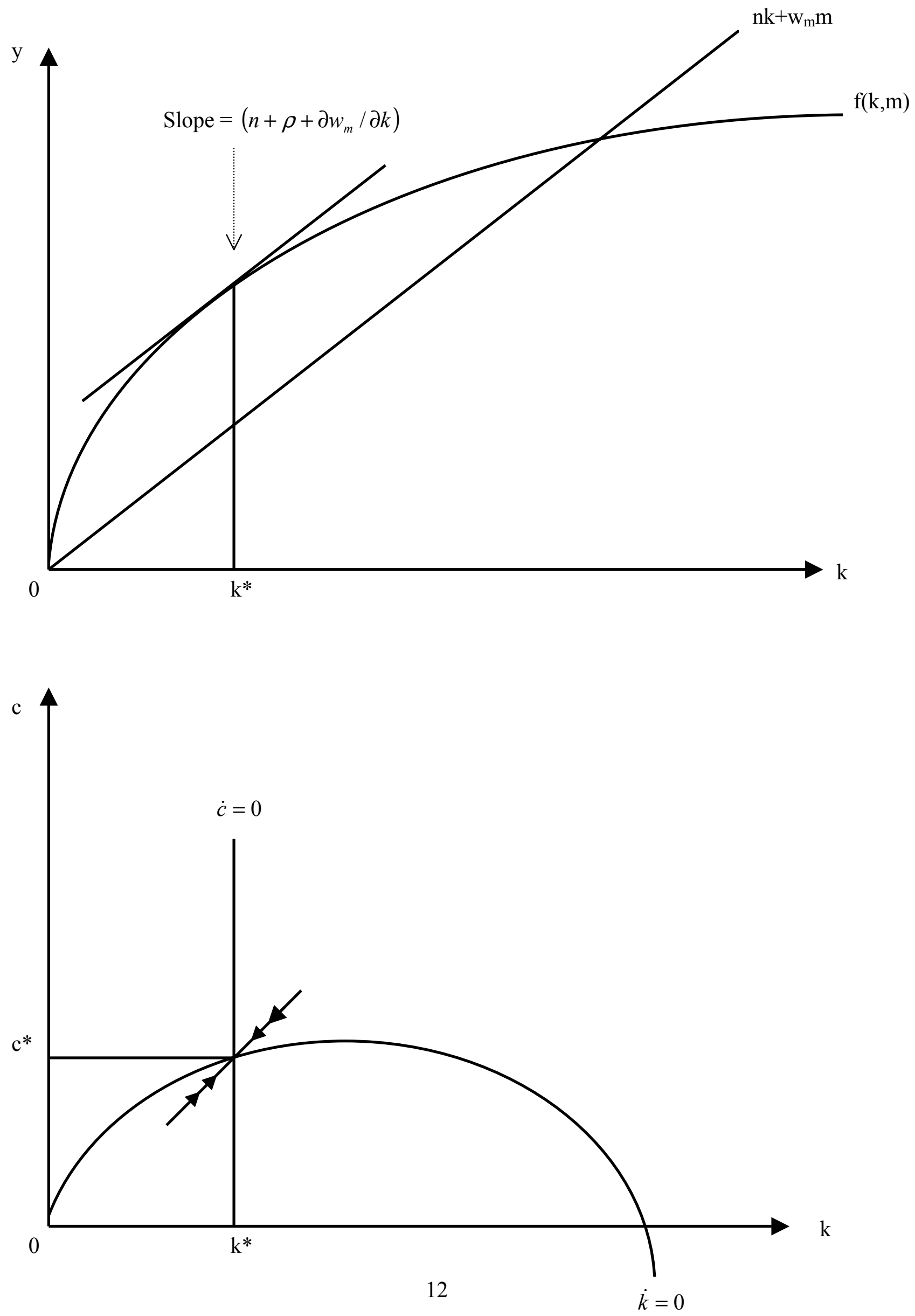
The above result can be explained more intuitively by using a Cobb-Douglas production function and a constant elasticity of substitution utility function. The production function is given by $y=k^{\varepsilon} m^{1-\varepsilon-\varepsilon^{\prime}}$. The maximization problem can be written as:

$$
\underset{\mathrm{c}}{\operatorname{Max}} \quad \int_{0}^{\infty} e^{-\rho t} \frac{c_{t}^{1-\theta}}{(1-\theta)} d t
$$

subject to

$$
\dot{k}=k^{\varepsilon} m^{1-\varepsilon-\varepsilon^{\prime}}-c-n k-w_{m} m
$$

where $\varepsilon$ and $\varepsilon^{\prime}$ are the Cobb-Douglas exponents of capital and labour respectively.

The terms $k=\mathrm{K} / \mathrm{L}$ and $m=\mathrm{M} / \mathrm{L}$. By using the procedures in the text we arrive at the following solution:

$$
\frac{\dot{c}}{c}=\frac{\varepsilon k^{\varepsilon-1} m^{1-\varepsilon-\varepsilon^{\prime}}\left[\left(1-\beta^{\prime}\right)+\beta^{\prime}\left(\varepsilon+\varepsilon^{\prime}\right)\right]-(n+\rho)}{\theta}
$$

In the case of zero migration (36) reduces to:

$$
\left.\frac{\dot{c}}{c}\right|_{m=o}=\frac{\varepsilon k^{\varepsilon-1}-(n+\rho)}{\theta}
$$

Hence:

$$
\frac{\dot{c}}{c} \geq\left.\frac{\dot{c}}{c}\right|_{m=o} \quad \text { if and only if } 1 \geq m^{1-\varepsilon-\varepsilon^{\prime}}\left[\left(1-\beta^{\prime}\right)+\beta^{\prime}\left(\varepsilon+\varepsilon^{\prime}\right)\right]
$$

We specifically consider the case where $\frac{\dot{c}}{c}$ for domestic residents with migrants is less than without illegal migrants. This requires that:

$$
1<m^{1-\varepsilon-\varepsilon^{\prime}}\left[\left(1-\beta^{\prime}\right)+\beta^{\prime}\left(\varepsilon+\varepsilon^{\prime}\right)\right]
$$

It is trivial to show that $\left[\left(1-\beta^{\prime}\right)+\beta^{\prime}\left(\varepsilon+\varepsilon^{\prime}\right)\right]<1$. Hence, for $\left(38^{\prime}\right)$ to hold, we require that $m>1$, i.e. the number of illegal migrants is greater than the domestic labour 
force. Thus, under most reasonable conditions, illegal migrants are beneficial to domestic consumption (provided the illegal migrants and domestic labour are imperfect substitutes).

\section{CONCLUSION}

In this paper it is established that the impact on resident consumption with illegal migrants depends on the degree of substitution between migrant and domestic labour. In the case where they are perfect substitutes (the first model) per capita domestic consumption always falls, while in the case when they enter the production process as another factor, the effect on resident domestic consumption is ambiguous. However, for the Cobb-Douglas case and in most realistic scenarios, illegal migrants raise the long term per capita consumption of domestic residents. From a policy perspective, resources should not be used to police illegal migrants that are imperfect substitutes for domestic labour. Some countries appear to be already following this policy. 


\section{NOTES}

1. See for example, Hillman and Weiss (1999).

2. A two-sector growth model with illegal migrants, without optimization, has been analysed by Hazari and Sgro (2000). This present paper concentrates on optimization and growth.

3. See for example, Hillman and Weiss (1999).

4. Other migration functions are possible including the addition of a stock variable to capture the effect on migration of the existing stock of illegal migrants already in the receiving country. The addition of such a stock variable can be handled easily and does not add anything of substance to our results.

5. This is in the tradition of separating domestic welfare from total welfare as in the international trade literature. See for example, Bhagwati and Srinivasan (1983).

6. This formulation is similar to that which applies in discrimination literature.

Further details about this formulation and the generation of a surplus can be found in Sgro (1986). 


\section{REFERENCES}

Barro, R and X. Sala-I-Martin (1995) Economic Growth, Singapore, McGraw Hill.

Bhagwati, J.N and T. N. Srinivasan (1983). Lectures on International Trade. Cambridge Mass: MIT Press

Borjas, G.J. (1995) The Economic Benefits from Immigration. Journal of Economic Perspectives. Vol 9, No 2, p3-22

Inada, K.I. (1966) Investment in fixed capital and the stability of growth equilibrium. Review of Economic Studies 33, p19-30

Hazari, B. R. and P. M. Sgro (2000). Illegal Migration, Border Enforcement and Growth Review of Development Economics, 4, (3) p258-267.

Hillman, A. L. and W. Weiss (1999). A Theory of Permissible Illegal Migration European Journal of Political Economy, Vol 15,(4) p585-604

Sgro, P.M. (1986) Factor Substitution and Discrimination in Labour Markets The Southern Economic Journal 52.4, p1103-114. 